\title{
МЕХАНИЗМ ЭФФЕКТИВНОСТИ УПРАВЛЕНИЯ СОЦИАЛЬНО-ЭКОНОМИЧЕСКИМ РАЗВИТИЕМ РЕГИОНОВ
}

\author{
(c) 2021 Иванова Наталия Александровна \\ доцент кафедры «Экономика высокотехнологичных производств» \\ Санкт-Петербургский государственный университет аэрокосмического приборостроения, \\ Россия, Санкт-Петербург \\ E-mail: prekrasnova.v@mail.ru
}

В предложенной статье объектом исследования является механизм эффективности управления социально-экономическим развитием регионов, а также достижение устойчивого экономического роста и развитие конкурентоспособной национальной экономики. Развивающаяся рыночная экономика предполагает аккумуляцию теоретических достижений и оценку их воздействия на собственную среду. Современный период характеризуется с одной стороны, эволюцией всех организационно-хозяйственных форм экономической деятельности, активностью компаний, а с другой стороны - возрастанием конкурентного напряжения на мировых рынках, формированием специфических форм конкурентной борьбы, тенденцией к интеграции в мирохозяйственные процессы, что предопределяет изменение приоритетов в направлении качественного развития реального сектора экономики. Новизной исследования является смена приоритетов в экономическом развитии, отказ от традиционной промышленной политики и переход к новой инновационной.

Ключевые слова: механизм, социально-экономические системы, региональная политика, институциональный механизм. наукоемкая экономика.

В экономике и управлении использование термина «механизм» в различных словосочетаниях используется довольно широко.

К числу наиболее распространенных понятий относятся: механизм хозяйствования, механизм управления, экономический механизм регулирования, организационно-экономический механизм и т.д.

В число обобщенных трактовок данного понятия можно отнести комплекс рычагов, используемых в управлении» [1].

По-нашему мнению, такие понятия могут использоваться при описании рассматриваемых явлений и имеют преимущественно познавательный характер.

Для исследования конкретных теоретических проблем и решения практических задач они малопригодны, так как охватывают слишком широкий спектр предметных областей, каждая из которых имеет присущий ей объект исследования, предмет и соответствующую методологию.

Вторую группу образуют понятия, имеющие более конкретный характер. При использовании таких трактовок механизм рассматривается, прежде всего, как результат взаимодействия отдельных элементов в различных процессах и явлениях, происходящих в экономике и управлении.
Для решения методологических и практических задач более конструктивной является вторая позиция, так как она больше соответствует основам теории механизмов, а также имеет большую ценность для принятия конкретных решений.

В экономике моделью механизма управления является контур управления.

Изучение специальной литературы свидетельствует, что большинство авторов рассматривают простейшую модель контура управления как замкнутую цепь, состоящую из управляющей и управляемой подсистем. Другие формулировки мало чем отличаются от приведенной, так как она является наиболее полной [2].

По нашему мнению, контур управления является динамической моделью используемых механизмов управления, которая отражает содержание происходящих в системе управления процессов.

В предлагаемой нами интерпретации контур управления представляет собой первичный элемент системы управления, который является основой построения институционального механизма управления.

В рамках отдельного контура управления осуществляется процесс достижения поставленной цели посредством преобразования информации, 
отражающий состояние процессов и явлений, происходящих в объекте управления в соответствующие управленческие воздействия.

Ядро контура управления составляют цели, набор различного рода управленческих воздействий, необходимых для её достижения, а также состав функций, образующих управленческий цикл, в рамках которого осуществляется полноценная деятельность аппарата управления.

Цель представляет собой планируемый результат, выступающий как единство желаемого и возможного, определяемого на основе предвидения и экономических расчетов.

В управлении ей принадлежит основополагающее место, так как правильно сформулированная цель позволяет определить состав и содержание используемых экономических регуляторов, выполняемых органами управления функций и используемой при этом информации.

В качестве объектов управления могут выступать организации государственного и негосударственного сектора, предоставляющие услуги населению и предпринимателям, осуществляющим инновационную деятельность в определенном регионе.

Регулирующий блок включает в свой состав научно обоснованный набор экономических форм, методов и инструментов, которые используются для достижения поставленных целей.

Институциональный блок по своему содержанию является основой государственного институционального механизма.

Характеристики данных компонентов системы управления находят свое отражение в соответствующих нормативных правовых актах, которые образуют институциональный механизм управления, регулирующий определенный вид экономической деятельности по оказанию услуг населению регионов.

Институциональный механизм включает два вида контуров управления:

- в деятельности уполномоченных государственных органов по отношению к организациям частного сектора, которые осуществляют свою деятельность в условиях свободного рынка.

- включает в себя цели, задачи и функции управления по отношению к организациям, деятельность которых финансируется из средств бюджета.

Ключевое значение в рассматриваемом контуре управления принадлежит информационному блоку, отражающему уровень обеспечен- ности населения регионов услугами.

В этой связи необходимо определить:

- регулируемую сферу деятельности, для которой можно установить измеримый результат.

- регулятор (состав регуляторов), используемых для достижения целевого значения конечного результата в регулируемой деятельности.

- функции уполномоченного органа, ответственного за использование соответствующего регулятора.

Для решения задач устойчивого и динамичного экономического роста страны целесообразен новый подход в политике, предполагающий, прежде всего, поиск приемлемых и эффективных методов и инструментов оценки уровня и направлений социально-экономического развития территорий, обоснование выбора методического аппарата к определению экономического профиля территории. Это позволит дать однозначную трактовку состояния экономики, провести достоверную оценку региональной специализации и географической концентрации промышленности, а также выявить узкие места и возможности развития эффективной специализации и диверсификации экономики, что представляет высокую ценность как с исследовательской, так и управленческой точки зрения [3].

В данном случае возникает вопрос о необходимости реализации такой политики на региональном уровне, которая будет нацелена на устранение негативной тенденции и приведение процессов, связанных с социальноэкономическим развитием, в сбалансированное состояние.

В свете новых задач эффективное развитие всех территорий страны представляется важнейшим аспектом в работе государства на ближайшие годы, назрела необходимость модернизации политики в данном направлении на основе современных принципов и подходов.

До настоящего времени остается актуальной тема поиска решений проблемы региональных различий и методологии исследования вклада каждого региона в достижении экономического роста.

Международный опыт в данной сфере демонстрирует широкий набор инструментов в области устойчивого регионального развития, предназначенных для сглаживания территориальных различий.

Как показала практика, в благополучных государствах политика выравнивания ори- 
ентируется на «подтягивание» отстающих в развитии регионов до уровня успешных. В развивающихся странах нашла широкое применение политика поиска и развития потенциально привлекательных «точек роста» с параллельным процессом выравнивания различий в социально-экономическом развитии регионов.

Система регулирования развития территории должна базироваться на пространственном подходе, составляющими которого являются:

- повышение уровня территориальной мобильности факторов производства, развитие межрегиональных и международных хозяйственных связей, что предполагает развитие рыночной, производственной, транспортной, коммуникационной и логистической инфраструктуры;

- размещение промышленных предприятий с точки зрения повышения эффективности использования потенциала регионов, диверсификации региональной структуры экономики и формирования «точек роста» на основе «умной» специализации;

- развитие малого бизнеса с целью удовлетворения первоочередных потребностей населения и обслуживания сферы производства;

- обеспечение инклюзивного развития пространства страны с точки зрения равного доступа населения всех регионов и населенных пунктов к социальным благам и услугам.

Основной целью формирования новой политики пространственного развития является обеспечение сбалансированного развития его территории с акцентом на создание наукоемких производств на основе эффективной специализации экономики регионов и равного доступа населения к социальным услугам, т.е. инклюзивного развития.

В основу формирования политики пространственного развития экономики должны быть положены следующие принципы:

- единство стратегического развития территорий страны, учитывающее интересы власти, бизнеса и населения;

- устойчивость территориального развития, основанная преимущественно на становлении наукоемких секторов экономики, совершенствовании региональной структуры и обеспечении инклюзивного социального развития;

- открытость и публичность принятия решений в сфере пространственного развития;

- концентрация ресурсов и градостроитель- ной активности в точках роста и др.

Приоритетами реализации политики пространственного развития должны быть:

- устойчивое развитие как системное сочетание экономического, социального и экологического аспектов пространственного развития страны;

- обеспечение социальных стандартов для жителей городов и сел, рациональное расселение населения с целью достижения эффективного развития экономики регионов;

- формирование городских агломераций, создание сети подлинно новых «умных» и «зеленых» городов-спутников;

- баланс предпринимательской инициативы, потребностей инвестора и стратегических приоритетов развития региона.

Реализация принципов «умной» специализации на практике осуществляется через формирование соответствующих механизмов управления.

Данный термин довольно широко используется представителями различных отраслей знаний.

Единого взгляда на его содержание еще не сформировалось.

Для реализации на практике принципа инклюзивного пространственного развития каждого вида услуг необходимо формировать соответствующий ей институциональный механизм управления.

С точки зрения экономической целесообразности и управленческой эффективности региональной политики для регионов с их уровнем социально-экономического развития оптимальным подходом является комбинирование теорий конвергенции, полюсов роста, взаимной и кумулятивной обусловленности, пространственных эффектов и т.д [4].

В основе теоретических концепций лежат следующие методологические установки:

- межрегиональные диспропорции являются органичной характеристикой многокомпонентной региональной системы страны, которая оценивается количественными признаками;

- необходимо расценивать диагностику диспропорций как отдельный вид аналитического исследования, включающий собственные цели, задачи, характеристики и технологии;

- все представленные методы и подходы затрагивают основную проблему исследования - вопрос несбалансированности территориаль- 
ного развития и несут в себе рейтинговые и ранговые методы комплексных оценок, которые наряду с многочисленными достоинствами имеют и ряд методических неясностей.

Поляризованная политика, выражающаяся в активной поддержке территорий-лидеров (своеобразных «полюсов роста») только усугубляет имеющиеся на межрегиональном уровне диспропорции, приводя к росту количества проблемных (отсталых и депрессивных) регионов. И, напротив, выравнивающая политика, нацеленная на поддержку отстающих регионов с целью приближения их уровня к лидирующим, демонстрирует положительные результаты. По итогам ее применения уменьшается разрыв между более и менее успешными регионами, сокращается количество проблемных территорий.
В целях устранения территориальных диспропорций и достижения гармоничного развития регионов необходимо перейти от политики стимулирования успешных городов и областей, закрепленной в средне- и долгосрочных стратегических документах страны (программах, прогнозных схемах и т.д.) к политике выборочной поддержки проблемных территорий на базе выравнивающей селективной региональной политики.

Таким образом, с учетом прогресса новых технологий, новой конкурентной среды жесткие подходы к организации управления уступают место принципам инновационности. В сложившихся обстоятельствах большое значение приобретает механизм управления социальноэкономическим развитием регионов, отражающих современный этап развития экономики России. 